Oxford Review of Economic Policy, Volume 34, Number 3, 2018, pp. 461-474

\title{
Job polarization: an historical perspective
}

\author{
Erik Buyst, * Maarten Goos, ${ }^{* *}$ and Anna Salomons***
}

\begin{abstract}
This paper uses historical labour market data for Belgium for the period 1846-2011 to illustrate how the employment impacts of the ongoing Digital Revolution after 1980 compare to those of the Second Industrial Revolution before 1980. Our analyses show that the period 1846-1947 was characterized by economy-wide skill-upgrading due to an increase in the demand for skilled relative to unskilled workers because of skill-biased technological change (SBTC). The period 1947-81 is characterized by particularly high labour market turbulence, in part due to a gradual switch from economywide skill-upgrading to job polarization. Consequently, the impact of the ongoing Digital Revolution on labour markets after 1980 is not uniquely characterized by exceptionally high labour market turbulence but by the nature of changes in the composition of jobs, namely a process of job polarization. To explain job polarization, the paper discusses the hypothesis of Routine-Biased Technological Change (RBTC) that has recently emerged in the academic literature.
\end{abstract}

Keywords: job polarization, technological change, historical census data

JEL classification: J24, J62, O30

\section{Introduction}

The Second Industrial Revolution, with the invention of steam power, electricity, the automobile, modern chemistry, and the telephone, caused a sea change in manufacturing, starting around 1850 and lasting until about 1980. Large plants replaced small artisanal workshops. On the new factory floors, economies of scale came from workers operating new machinery (Katz and Margo, 2014). Because machine operators required some but not much training, the gains from specialization provided many unskilled farmers with opportunities to move into better-paid, medium-skilled, blue-collar jobs, such as machine operators. Together with an increase in medium-skilled and skilled white-collar employment in manufacturing as well as in services, such as office clerks and managers, this led to skill-upgrading in the overall economy. Economists call this process of skill-upgrading due to technological progress 'skill-biased technological change' or SBTC, capturing the

*KU Leuven, e-mail: erik.buyst@kuleuven.be

**Utrecht University, e-mail: m.goos@uu.nl

***Utrecht University, e-mail: a.m.salomons@uu.nl

We thank John Muellbauer, Abigail Adams, and seminar participants at Oxford University for excellent suggestions. Salomons gratefully acknowledges funding from the Netherlands Organisation for Scientific Research under the Veni scheme.

doi:10.1093/oxrep/gry003

(C) The Authors 2018. Published by Oxford University Press.

For permissions please e-mail: journals.permissions@oup.com 
idea that technological progress results in an increase in the demand for (medium-)skilled relative to unskilled workers (Katz and Murphy, 1992). Skill-upgrading was also made possible by a contemporaneous increase in the supply of (medium-)skilled relative to unskilled workers due to the rapid expansion of the education system. In fact, the increase in the relative supply of skills outpaced the increase in demand, such that skills were relatively abundant, thereby reducing the skill premium and overall wage inequality. In this way, technological progress before 1980 resulted in economic growth, skill-upgrading, mass education, and lower overall wage inequality (Goldin and Katz, 2008).

Beginning in the 1980s, the impact of the ongoing Digital Revolution on labour markets is very different. The reason for this is that computers can codify and perform more efficiently routine tasks mainly done by medium-skilled workers, such as machine operators and office clerks. But the tasks done by unskilled workers, such as waiters or cleaners, and skilled workers, such as managers and computer programmers, are non-routine in nature and therefore not easily codified and performed by computers. In short, underlying skill-upgrading there is a more nuanced process of how worker skills interact with digital technologies. Economists call this more nuanced process 'routinebiased technological change' or RBTC (Acemoglu and Autor, 2011). In contrast to SBTC and skill-upgrading, RBTC is consistent with the recent phenomenon of job polarization-i.e. an increase in the relative employment of non-routine skilled and unskilled jobs at the expense of routine medium-skilled jobs. At the same time, growth in educational attainment rates has faltered in many advanced economies since 1980, reducing growth in skill supplies, thereby increasing the skill premium and upper-tail and overall wage inequality. In sum, the impact of the ongoing Digital Revolution is markedly different from that of previous episodes of economic development.

This paper provides a better understanding of the historical differences in relative employment changes before and after 1980 using unique census data for Belgium between 1846 and 2011. Our analyses show that the period 1846-1947 was characterized by economy-wide skill-upgrading, consistent with the SBTC hypothesis of technological progress. The period $1947-81$ is characterized by particularly high labour market turbulence, in part due to a gradual switch from a process of economy-wide skill-upgrading to job polarization. Consequently, we show that the impact of the ongoing Digital Revolution on labour markets after 1980 is not uniquely characterized by exceptionally high labour market turbulence but by the nature of changes in the composition of jobs, namely a process of job polarization due to RBTC.

The remainder of this paper is organized as follows. Section II briefly describes our historical dataset. The analysis in section III focuses on the period after 1981, and section IV discusses the period 1846-1981. Throughout, economic thinking about how technological progress can explain the differences in observed employment changes is discussed. Finally, section V concludes.

\section{Data}

We use historical labour market data for Belgium, one of the first countries to industrialize. In particular, we use data from 16 Population Censuses over the 165-year period between 1846 and 2011. Employment is counted as the labour force, which includes 
gainfully occupied workers as well as the unemployed, but excludes students, retirees, rentiers, those staying at home, e.g. to take care of children, individuals in institutions, vagrants, and beggars. For each of the censuses, every resident has to indicate his or her (main) occupation, with the unemployed usually declaring their previous occupation. The occupation classification is made consistent over time and is comparable but not identical to either the current standard ISCO-occupation or the NACE-industry classifications. Therefore, 'occupation' and 'sector' are used interchangeably in this paper. For more detailed information about the construction of our data, see Buyst (2011).

We count employment in each of 22 subsectors spanning the entire economy, i.e. agriculture, manufacturing, as well as services. We drop the subsector 'unspecified occupation' as it is difficult to interpret the nature of employment in it, as well as employment in 'domestic services' and 'religion' because of a lack of wage information. As is common in the job polarization literature, our main analyses are done using data for the private sector only, spanning 20 out of 22 subsectors. Public sectors 'education' and 'government' are introduced later in the paper for reasons that will become clear below. Finally, we rank sectors by their average daily wage in 1981, the earliest period for which wage data are available for each of the 22 subsectors. We keep this ranking fixed throughout our analyses, but using wage information from a different year to rank sectors does not qualitatively change our results.

\section{Job polarization after 1981}

In a seminal contribution, Autor et al. (2003) argued that routine tasks can be done either by workers or by computer capital. ${ }^{1}$ The reason for this is that routine tasks are defined by their systematic and structured content and can therefore be increasingly codified in software and embodied in digital capital, whereas non-routine tasks are harder to automate. As a result, capital accumulation leads to an increase in the number of routine tasks in the economy, known as routine-biased technological change (RBTC), while decreasing the demand for routine relative to non-routine labour tasks done by workers. Because routine labour tasks are concentrated in middling-paid jobs, RBTC leads to a hollowing out of labour demand, also known as job polarization. Several studies use data from the 1980s onwards to document and explain the existence of job polarization in advanced economies. See, for example, Autor et al. (2006), Acemoglu and Autor (2011), and Autor and Dorn (2013) for the US; Goos and Manning (2007) for the UK; and Goos et al. $(2009,2014)$ for Europe.

To illustrate job polarization across private sectors in Belgium, columns (1)-(3) of Table 1 rank 20 private sectors by their wage in 1981, from high to low. The two highest-paid sectors with substantial employment in 1981 are 'financial and commercial services, and real estate' and 'legal and engineering professions'. The two lowest-paid sectors are 'personnel and miscellaneous services' and 'other social services'. Column (4) of Table 1 lists the employment share change (in percentage points) for each sector between 1981 and 2011, showing that there was relative employment growth in the highest-paid and lowest-paid sectors at the expense of employment in middling sectors, i.e. there was job polarization. Figure 1 visualizes this by plotting the actual percentage

1 See Autor (2013) for an overview. 


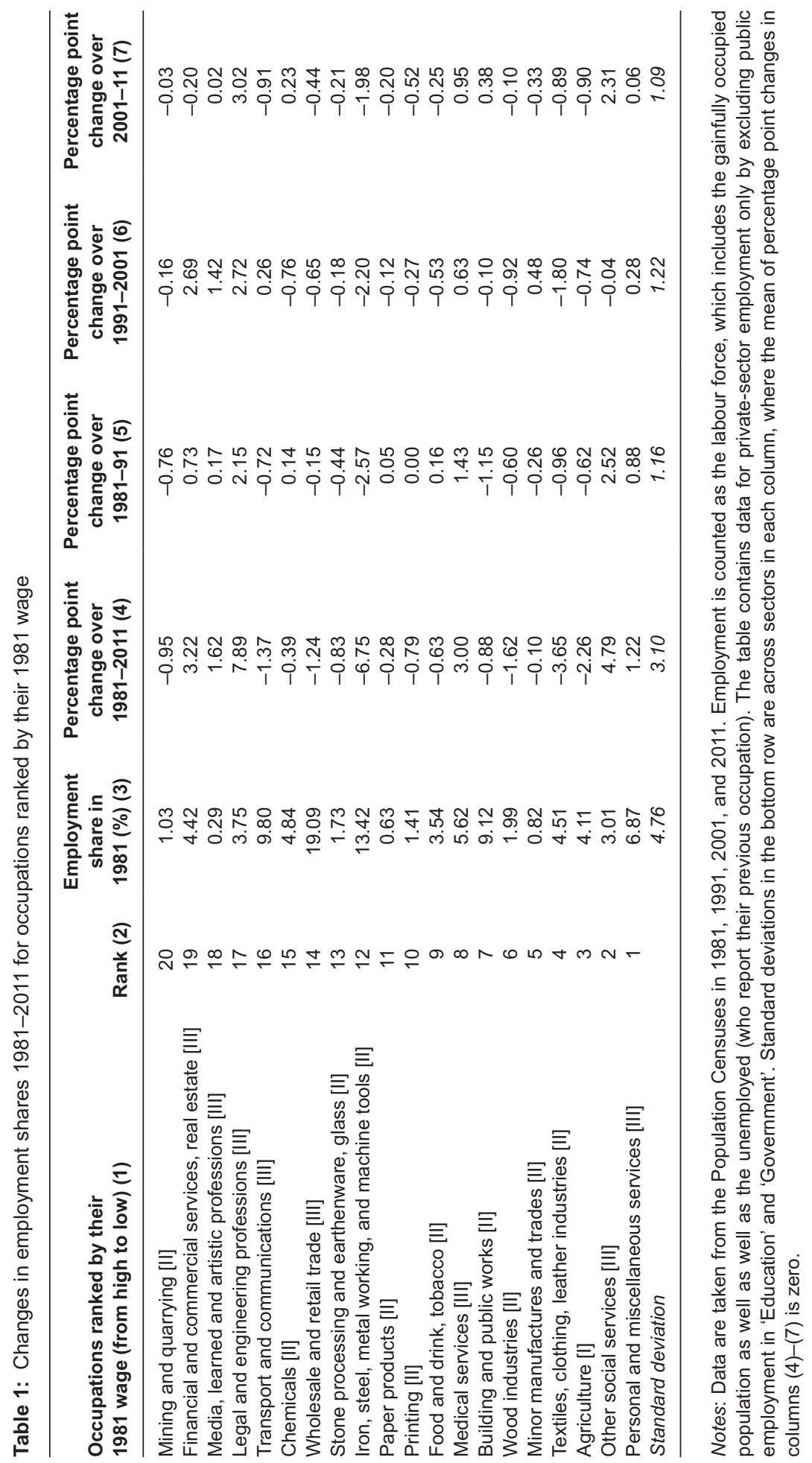


Figure 1: Percentage point change in employment shares across sectors, 1981-2011

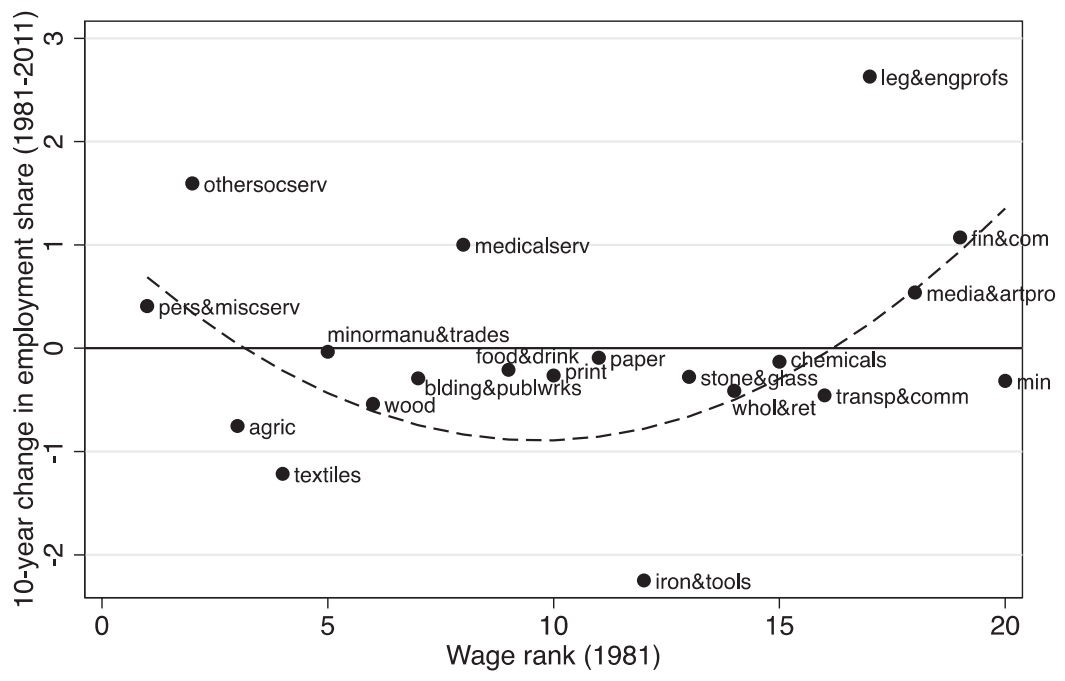

- Actual change ---- - Predicted change

point changes from column (4) of Table 1 on the vertical axis against the ranking of sectors in column (2) on the horizontal axis. The dashed line plots predictions from a weighted regression of percentage point changes in sectoral employment shares on to the wage rank of a sector and its square, weighted by sectoral employment in 1981. The U-shaped relationship between employment share changes and wage rank across sectors is consistent with the hypothesis that employment is polarizing into high-paid and low-paid jobs.

Figure 1 is in line with existing evidence from different data sources. Instead of using census data, Goos et al. (2014) use labour force survey data for 16 European countries between 1993 and 2010. Their findings show that in Belgium the employment share for the eight highest-paid occupations, accounting for 34 per cent of total employment in 1993, increased by 9 percentage points between 1993 and 2010. The employment share for the nine middling occupations, accounting for 49 per cent of total employment in 1993, decreased by 12.7 percentage points. And the employment share of the four lowest-paid occupations, accounting for 17 per cent in 1993, increased by 3 percentage points. These changes are both quantitatively and qualitatively similar to those reported in Figure 1.

To explain job polarization, Goos et al. (2014) point to the introduction of personal computers in the late 1970s/early 1980s and consequent advances in digital technologies. To understand why, first consider the reallocation of middling to low-paid employment. Up until now, digital capital has had a comparative advantage in doing routine tasks concentrated in middling occupations relative to non-routine manual tasks used intensively in low-paid work. ${ }^{2}$ As a result, it has been more cost efficient for new machines to substitute

2 For example, most of us know how to be a good waiter in a restaurant, but none of us knows how to write this down in software code. Autor (2015) coins this 'Polanyi's paradox', after philosopher Michael Polanyi. In his book The Tacit Dimension, Polanyi (1966) argues that, to a large extent, human capabilities 
for routine tasks done by medium-skilled machine operators in 'iron, steel, metal working and machine tools' than for non-routine manual tasks done by unskilled 'personal and miscellaneous services' workers such as cleaners. Furthermore, consumer demand for low-paid services is relatively price-inelastic and income-elastic. This is important if technological progress is leading to a relative cost-disadvantage for low-paid services, but this cost-disadvantage (and consequent falls in relative product and therefore labour demand) are quantitatively unimportant if demand for low-paid services is price-inelastic or income-elastic. A similar logic applies to the reallocation of workers from middling to high-paid jobs. So far, digital capital has been more efficient at automating routine tasks concentrated in medium-skilled occupations than non-routine cognitive and interactive tasks used intensively by skilled workers in high-paid jobs, in which there often are strong complementarities between digital capital and labour. For example, computers complement the work of professionals in high-paid 'legal and engineering professions'. Moreover, consumer demand for products and services using high-paid workers intensively is generally more price-elastic as well as income-elastic, further contributing to the reallocation of employment from middling jobs to higher-paid work.

\section{The period before 1981}

Table 2 shows 10-year percentage-point changes for the period 1846-1981 by sector. A first point to notice from column (3) is how different the distribution of employment across sectors was in 1846 compared to 1981. In 1846, 49 per cent of workers were employed in 'agriculture' and 27 per cent in 'textiles, clothing and leather industries'. By 1981, both employment shares had dropped to about 4 per cent. By contrast, the share of workers in 'wholesale and retail trade' increased from 3 per cent in 1846 to 19 per cent in 1981. Similarly, between 1846 and 1981, the share of workers employed in 'iron, steel, metal working and machine tools' increased from 3 per cent to 13 per cent (with a peak of 16 per cent in 1961). Finally, the fraction of workers employed in 'transport and communication' increased from 1 per cent in 1846 to 10 per cent in 1981 . These changes illustrate the importance of labour market turbulence long before the start of the computer era. The bottom row of Table 2 shows the standard deviations of employment share changes across sectors for each sub-period, suggesting that turbulence was particularly strong in the periods 1890-1910 and 1947-81, even compared to the changes after 1981 given in Table 1. One way to discuss these changes further is to separate the period 1846-1981 into the two sub-periods 1846-1947 and 1947-1981.

\section{(i) Occupational upgrading: 1846 to 1947}

Figure 2 plots the average 10-year percentage-point changes between 1846 and 1947 against the ranking of sectors by their average wage in 1981 (just as in Figure 1), as

rely on tacit or subconscious knowledge, i.e. knowledge that cannot be formalized or put into exact words. The thesis of his book was summarized in the slogan 'we know more than we can tell', and Autor (2015) argues that this paradox is important in understanding why many jobs have not yet been automated. 


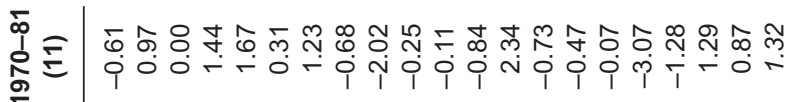

只

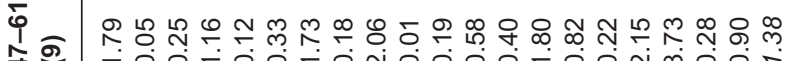

年

每

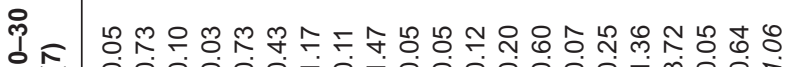

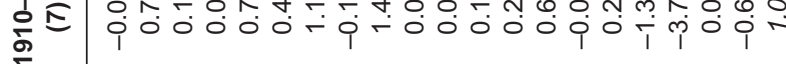

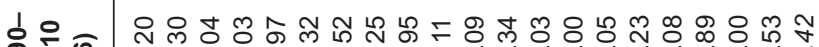

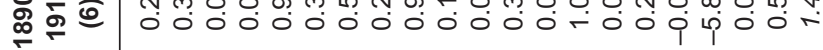

ㅇำ 으

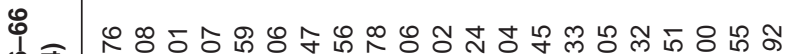

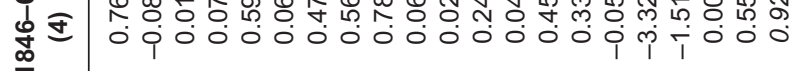

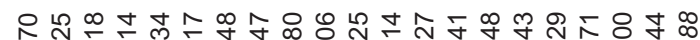

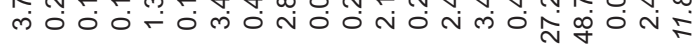

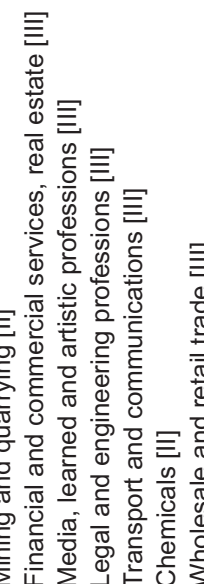


Figure 2: Percentage point change in employment shares across sectors, 1846-1930

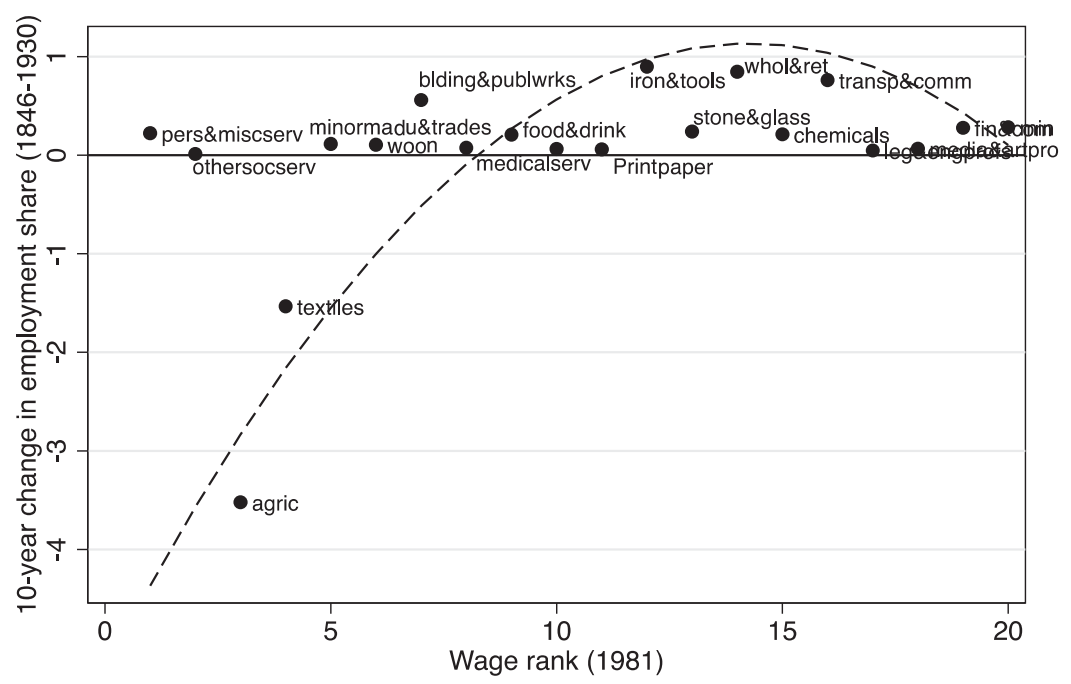

- Actual change ----- Predicted change

well as predictions from a weighted quadratic regression of this relationship, weighted by sectoral employment in 1846. Clearly, the period 1846-1947 is characterized by occupational upgrading rather than job polarization, with large movements out of 'agriculture' and 'textiles, clothing and leather industries' towards most other sectors and 'wholesale and retail trade', 'iron, steel, metal working and machine tools', and 'transport and communication' in particular. Intuitively, these changes correspond to Belgium's Second Industrial Revolution, with technological and organizational innovations occurring across the economy, especially but not exclusively in electric power generation and distribution, electrical machinery and equipment, civil/structural and chemical engineering, the combustion engine, railroads, aeronautics, telephony, and the rise of a factory system. ${ }^{3}$ As in other industrializing countries at the time, these 'Great Inventions' were mainly adopted between 1890 and 1930, leading to capital deepening and output growth. After 1930, despite a slowdown in capital deepening, output and employment growth remained strong due to an increase in total factor productivity (TFP) (Field, 2003; Alexopoulos and Cohen, 2016). ${ }^{4}$

Drawing almost entirely on evidence from manufacturing sectors only, the conventional wisdom among economists and economic historians is that technological change in the nineteenth century was predominantly de-skilling, i.e. that capital and unskilled labour substituted for (medium-)skilled labour. It is argued that the emergence of the factory system and the interchangeable parts revolution was unskilled-biased by replacing the work of (medium-)skilled artisans (metal-smiths, carpenters, weavers, etc.) with

3 Belgium's First Industrial Revolution started around 1800 and lasted until about 1850 and was focused on steam power, iron, and textiles.

${ }^{4}$ In fact, it was the observation of continued output growth after 1930, despite a slowdown in capital deepening, that made Solow (1957) introduce his 'Solow residual' or 'TFP-growth statistic' as a measure of technological progress. 
capital and unskilled labour (often children) — see Katz and Margo (2014) for a discussion. ${ }^{5}$ However, Goldin and Katz (1998) discuss why changes starting in the early twentieth century are better captured by a process of skill-upgrading due to skill-biased technological change (SBTC). They argue that SBTC emerged in manufacturing early in the twentieth century as particular technologies, known as batch and continuousprocess methods of production, spread. These continuous-process and batch methods differed from existing assembly lines in that raw materials are fed in and finished products emerge, with few hands intervening except for (medium-)skilled mechanics attending the production process. Consequently, the rise of the factory system and its assembly lines in the late nineteenth century first reduced the relative demand for skilled labour, leading to de-skilling, whereas the adoption of batch and continuous-process methods in the early twentieth century then increased it, leading to skill-upgrading due to SBTC. In sum, conventional wisdom suggests a discontinuity in the nature of machine-worker interaction in manufacturing during the second half of the nineteenth and first half of the twentieth century, from being de-skilling towards skill-upgrading because of SBTC.

However, Table 2 and Figure 2 do not fully support this view because they suggest that technological progress was skill-upgrading throughout the period 1846-1947, so in the second half of the nineteenth century, too. This difference arises because our data cover the entire economy rather than manufacturing sectors only and, in particular, include employment in agriculture and textile industries. Column (3) of Table 2 shows why this is important: in 1846, 49 per cent of all workers were employed in agriculture. Moreover, 'textiles, clothing and leather industries', by far the largest subsector in manufacturing, accounting for 27 per cent of overall employment in 1846, in large part includes the home-production of linen goods. These goods were mostly produced on farms outside the factory system, an activity that came under increasing pressure from the automation of textile production. In sum, what our data show is that, even if technological progress within the factory system was de-skilling for some (medium-) skilled artisans, the increase in relative demand for unskilled factory workers led to occupational upgrading for many more unskilled labourers in agriculture and textiles throughout the period 1846-1947, consistent with SBTC. This finding is in line with Katz and Margo (2014), who also find that de-skilling did not occur in the aggregate US economy during the second half of the nineteenth century.

The employment changes in Table 2 and Figure 2 are, of course, not exclusively driven by increases in the demand for (medium-)skilled relative to unskilled workers following SBTC. To show this, Goldin and Katz (2009) first document that US educational and occupational wage differentials were exceptionally high at the dawn of the twentieth century, and then decreased in several stages over the next eight decades. But starting in the early 1980s the skill premium rose sharply and by 2005 it was back at its 1915 level. Goldin and Katz (2009) then use a simple supply-demand framework to argue that the proximate cause for the pre-1980 fall and post-1980 rise of the skill premium has been an acceleration and then deceleration in the supply of (medium-)skilled relative to unskilled workers in the face of a (mostly) steady increase in the relative demand for skills due to SBTC. ${ }^{6}$

5 The Luddite rebellion of the nineteenth century is also a case in point. The Luddites were skilled weavers who rebelled against capitalists by destroying power-looms because they feared that this machinery would devalue their skill by allowing unskilled workers to do their jobs.

6 Autor et al. (1998), Autor et al. (2008), and Acemoglu and Autor (2011) provide some evidence of an acceleration in the relative demand for skilled workers in the 1970s or 1980s and a deceleration in the 1990s. 
Why did the relative supply of skilled workers increase so rapidly in the US between 1915 and 1980? Goldin and Katz (2008) document succinctly the reasons why the American educational system expanded rapidly between 1915 and 1980. The first reason, they argue, is that education was publically funded and provided by small and fiscally independent districts, bringing free education geographically close to many children in rural constituencies. Second, education was under secular control and gender neutral, such that it was open to both male and female children, from all religious backgrounds. Finally, education was practical in its curriculum, diverse in many dimensions, and forgiving. In a review of Goldin and Katz (2008), Acemoglu and Autor (2012) also point to the emergence of a political system that favoured majority preferences and their demand for education. All these virtues resulted in the rapid expansion of America's educational system between 1915 and 1980. That is, the changes in the US educational system between 1915 and 1980 were exceptional, and also in Europe there was mass education in the twentieth century (Goldin and Katz, 2008).

What about the impact on relative labour demand from changes in relative product demand during the twentieth century? Bessen (2017) shows that technologically advancing sectors exhibit a hump-shaped evolution of employment in the long run. To explain this pattern, he develops and tests a simple framework of consumer demand in which the price elasticity of demand for a good becomes more inelastic over time. In particular, a technology-induced decrease in the output price results in market expansion through additional consumers or the introduction of new product varieties. Because selection of new consumers or new product varieties is assumed to be positive, marginal consumers have a lower valuation of the good, or new product varieties are valued less by consumers. Moreover, it is realistic to assume that this decrease in marginal valuations eventually becomes larger in absolute value (i.e. price decreases have to become larger to attract additional consumers or it becomes harder to find new product varieties that are equally valued by consumers), such that the price elasticity of demand becomes more inelastic over time. Consequently, assuming technological progress also directly substitutes for workers, labour demand eventually decreases because the positive scale effects from increases in consumption dissipate over time. Bessen (2017) provides US evidence that this pattern in part explains the rise of manufacturing employment between 1810 and 1950, and the process of employment deindustrialization thereafter.

Although not reported in this paper, our data also show a hump-shaped pattern for manufacturing employment in Belgium, with a peak in 1930. Moreover, this pattern exists for nine out of our 11 manufacturing subsectors, with 'chemicals' and 'building and public works' being the non-surprising exceptions. Also interesting is that employment in these nine subsectors peaked at different points in time. For example, employment in food and clothing related industries peaked around 1930; in wood industries around 1950; in iron and steel related industries in 1960; and in paper and printing related industries in 1970. These results are similar to those discussed in Bessen (2017) for the US.

\section{(ii) From skill-upgrading to job polarization: 1947 to 1981}

So far, our analysis has shown a pattern of monotonic skill-upgrading in the aggregate economy from 1846 to 1947 in subsection IV(i), and a process of job polarization 
after 1981 in section III. How long did the process of skill-upgrading continue after 1947 before job polarization started to emerge? Surprisingly little is known about this. Barany and Siegel (2018) document for the US that employment polarization started before 1980, probably sometime in the 1960s or 1970s. Their explanation is based on Baumol's (1967) hypothesis of unbalanced productivity growth across sectors. In particular, they show that productivity growth increased in medium-paid manufacturing sectors relative to low-paid and high-paid services as early as the 1960s or 1970s, leading to a decrease in manufacturing employment shares and job polarization, albeit less strong, even before 1980. Juhn (1999) takes a similar sectoral approach to estimate changes in labour demand by wage percentile between 1940 and 1990 in the US, also finding that there was moderate job polarization already in the 1970s. In line with these studies, Table 2 and Figure 3 show similar evidence for Belgium. From the 1950s onwards, the pattern of employment share changes morphed from skill-upgrading into job polarization. What this evidence suggests is that the employment impact of ongoing technological progress started before the introduction of personal computers, with the release of the Apple II home computer in 1977 and the IBM-PC personal computer in 1981. Instead, the seeds of job polarization were planted long before, perhaps in part by the introduction of large-scale mainframe computing in the late 1950s.

The bottom line of Table 2 suggests that the reversal from skill-upgrading to job polarization between 1947 and 1981 was a particularly turbulent period for the Belgian labour market. Moreover, note that the sectors listed in Table 2 only include private-sector employment, as is usually done in the job polarization literature. To see what happened to public-sector employment, Figure 4 shows the evolution (in absolute numbers) of employment in 'education' and 'government'. 7 The time series for 'education' shows

Figure 3: Predicted percentage point change in employment shares across sectors by period, 1930-81

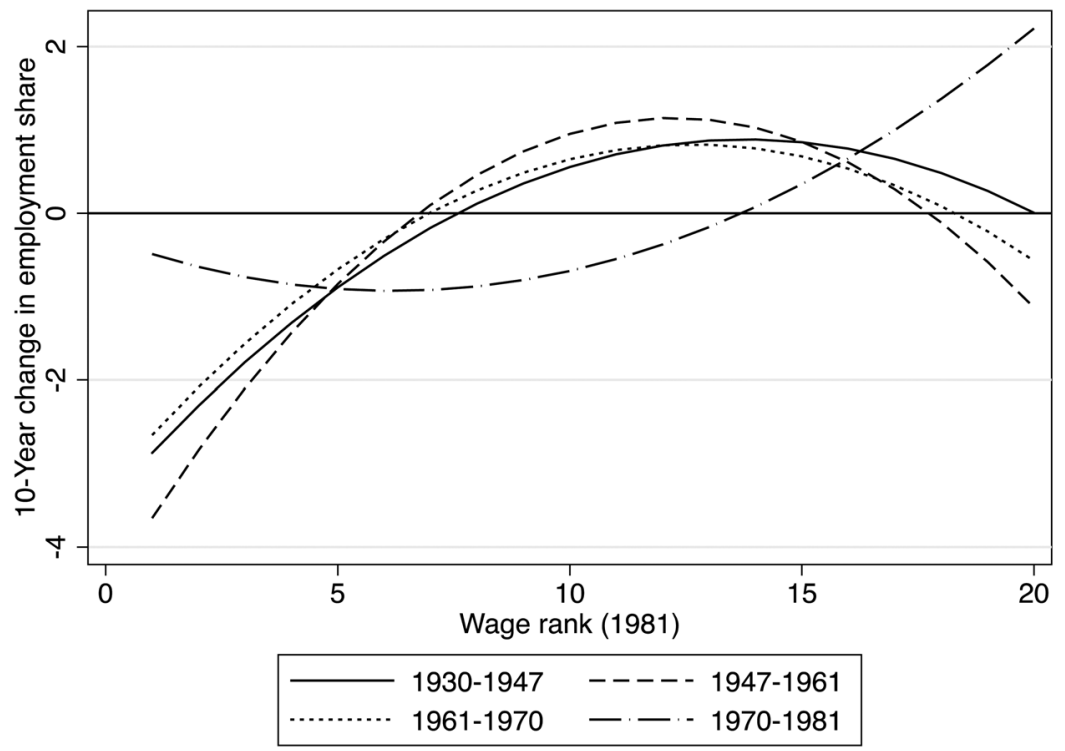

7 The sector 'medical services' listed in Tables 1 and 2 also partially contains public employment. 
Figure 4: Public-sector employment, 1846-2011

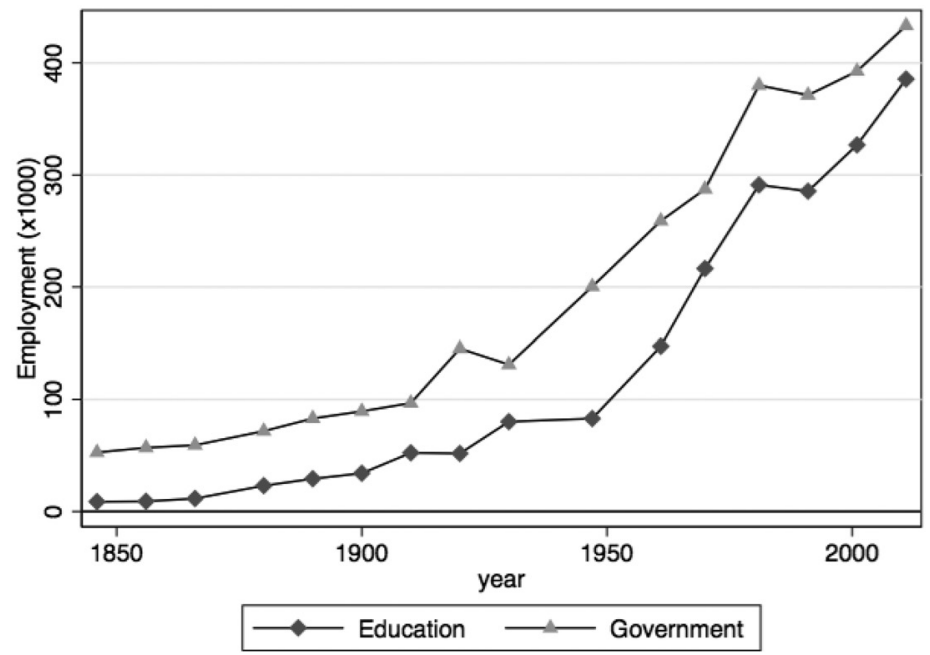

a modest increase to about $100 \mathrm{~K}$ in 1947 , after which employment grows five-fold faster to about $400 \mathrm{~K}$ in 2011, with particularly fast growth between 1947 and 1981. This increased growth between 1947 and 1981 can be explained by the rapid expansion of the Belgian secondary-education system and related increases in the minimum schoolleaving age. The 'government' sector also saw faster employment growth between 1930 and 1981, adding to job churning in the labour market. This faster growth is, in large part, due to the expansion of Belgium's social security system after $1944 .{ }^{8}$ In sum, the rapid expansion of public-sector employment between 1947 and 1980 amplified job turbulence that was already exceptionally high across private sectors.

\section{Conclusion}

To summarize our findings, Figure 5 shows the evolution (in absolute numbers) of employment in the primary sector (indicated by a ' $[\mathrm{I}]$ ' in the first rows of Tables 1 and 2), the secondary sector ('[II]'), and the tertiary sector ('[III]'). The period 1846-1947 was characterized by economy-wide skill-upgrading, driven by technological progress, as well as an increase in labour supply by farm workers to new factories and an increase in the relative supply of educated workers through investments in primary education. Moreover, most of the great inventions of the Second Industrial Revolution were general purpose technologies (GPT), resulting in many cheaper and various new products, leading to an increase in aggregate demand. The period 1947-81 was characterized by particularly large labour market turbulence in both the private and public sectors. The composition of private-sector employment changed because of a change in the nature of technological progress, from the Second Industrial Revolution to the Digital

8 Belgium's 'Social Pact' of 1944 was inspired by the British 'Beveridge Report' of 1942. 
Figure 5: Employment by main sector, 1846-2011

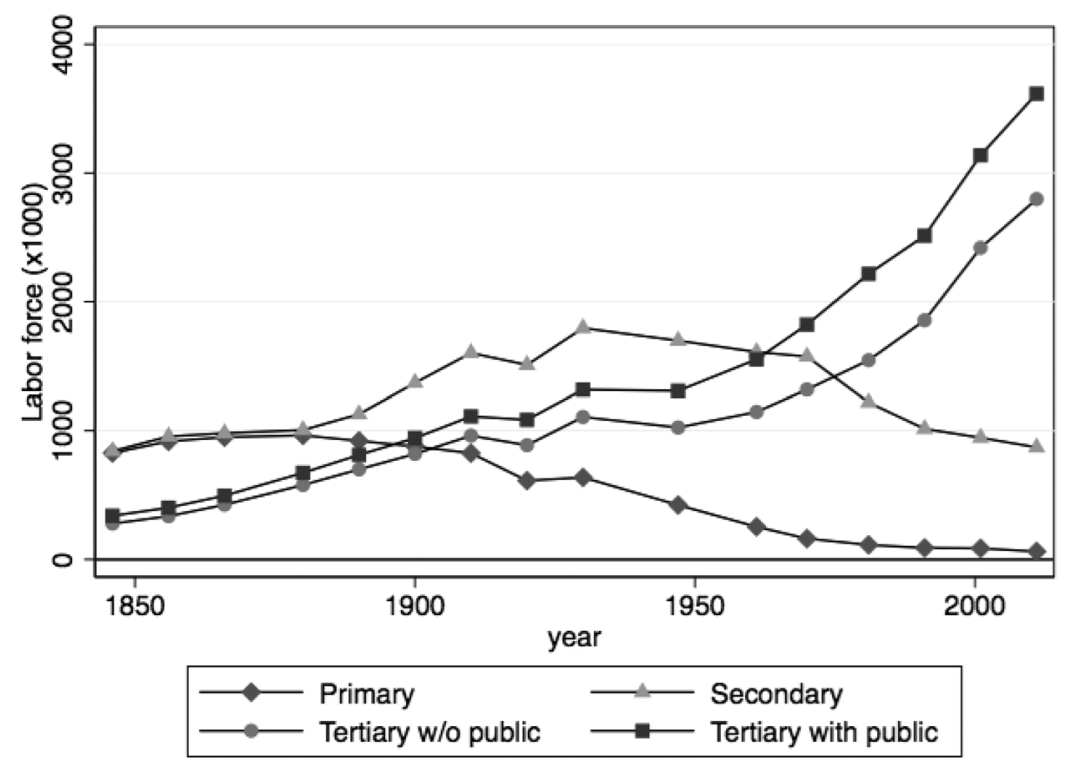

Revolution. This resulted in a decrease in secondary-sector and faster increase in tertiary-sector employment, made possible by the rapid expansion of the secondary-education system. Labour market turbulence between 1947 and 1981 was further amplified by increased growth in public-sector employment. The period after 1981 is characterized by the more complex nature of machine-worker interactions, (consequent) subsumed labour mobility between sectors, the still exploratory non-GPT nature of many digital applications, and a political economy less favourable to government investments in education and public employment. What uniquely characterizes today's labour markets is a process of job polarization that came into full swing after 1981, with increased employment in high-paid and low-paid jobs, at the expense of rapidly declining medium-paid jobs in manufacturing.

\section{References}

Acemoglu, D., and Autor, D. H. (2011), 'Skills, Tasks and Technologies: Implications for Employment and Earnings', in O. Ashenfelter and D. E. Card (eds), Handbook of Labor Economics, Vol. 4B, Amsterdam, Elsevier, 1043-171.

- - (2012), 'What Does Human Capital Do? A Review of Goldin and Katz's The Race between Education and Technology', Journal of Economic Literature, 50(2), 426-63.

Alexopoulos, M., and Cohen, J. (2016), 'The Medium is the Measure: Technical Change and Employment 1909-1949', Review of Economics and Statistics, 98(4), 792-810.

Autor, D. H. (2013), 'The "Task Approach" to Labor Markets', Journal of Labour Market Research, 46(3), 185-99.

- (2015), 'Why Are There Still So Many Jobs? The History and Future of Workplace Automation', Journal of Economic Perspectives, 29(3), 3-30. 
Autor, D. H., and Dorn, D. (2013), 'The Growth of Low-skill Service Jobs and the Polarization of the US Labor Market', American Economic Review, 103(5), 1553-97.

- Katz, L. F., and Kearney, M. S. (2006), 'The Polarization of the US Labor Market', American Economic Review, 96(2), 189-94.

_ _ _ (2008), 'Trends in US Wage Inequality: Revising the Revisionists', Review of Economics and Statistics, 90(2), 300-23.

- _ Krueger, A. B. (1998), 'Computing Inequality: Have Computers Changed the Labor Market?', Quarterly Journal of Economics, 113(4), 1169-213.

- Levy, F., and Murnane, R. J. (2003), 'The Skill Content of Recent Technological Change: An Empirical Exploration', Quarterly Journal of Economics, 118(4), 1279-333.

Barany, Z. L., and Siegel, C. (2018), 'Job Polarization and Structural Change', in American Economic Journal: Macroeconomics, 10(1), 57-89.

Baumol, W. J. (1967), 'Macroeconomics of Unbalanced Growth: Anatomy of an Urban Crisis', American Economic Review, 57(3), 415-26.

Bessen, J. (2017), 'Automation and Jobs: When Technology Boosts Employment', Boston University School of Law \& Economics Paper No. 17-09.

Buyst, E. (2011), 'Changes in the Occupational Structure of Belgium: New Estimates for the 18461910 Period', KU Leuven, mimeo.

Field, A. J. (2003), 'The Most Technologically Progressive Decade of the Century', American Economic Review, 93(4), 1399-413.

Goldin, C., and Katz, L. F. (1998), 'The Origins of Technology-Skill Complementarity', Quarterly Journal of Economics, 113(3), 693-732.

- - (2008), The Race Between Education and Technology, Cambridge, MA, Harvard University Press.

- - (2009), 'The Race Between Education and Technology: The Evolution of US Wage Differentials, 1890-2005', NBER Working Paper 12984.

Goos, M., and Manning, A. (2007), 'Lousy and Lovely Jobs: The Rising Polarization of Work in Britain', Review of Economics and Statistics, 89(1), 118-33.

- - Salomons, A. (2009), 'Job Polarization in Europe', American Economic Review, 99(2), 58-63.

_ _ _ (2014), 'Explaining Job Polarization: Routine-biased Technological Change and Offshoring', American Economic Review, 104(8), 2509-26.

Juhn, C. (1999), 'Wage Inequality and Demand for Skill: Evidence from Five Decades', Industrial and Labor Relations Review, 52(3), 42443.

Katz, L. F., and Margo, R. A. (2014), 'Technical Change and the Relative Demand for Skilled Labor: The United States in Historical Perspective', in L. P. Boustan, C. Frydman, and R. A. Margo (eds), Human Capital in History: The American Record, Chicago, IL, University of Chicago Press, 15-57.

- Murphy, K. M. (1992), 'Changes in Relative Wages, 1963-1987: Supply and Demand Factors', Quarterly Journal of Economics, 107(1), 35-78.

Polanyi, M. (1966), The Tacit Dimension, Chicago, IL, University of Chicago Press.

Solow, R. M. (1957), 'Technical Change and Aggregate Production Functions', Review of Economics and Statistics, 39(3), 312-20. 